\title{
Damage level prediction of non-reshaped berm breakwater using ANN, SVM and ANFIS models
}

\author{
Sukomal Mandal ${ }^{1}$, Subba $\mathrm{Rao}^{2}$, Harish N. ${ }^{1,2}$ and Lokesha ${ }^{2}$ \\ ${ }^{1}$ Ocean Engineering Division, National Institute of Oceanography, India \\ ${ }^{2}$ Department of Applied Mechanics and Hydraulics, National Institute of \\ Technology Karnataka, Surathkal, Srinivasnagar, India.
}

\begin{abstract}
The damage analysis of coastal structure is very important as it involves many design parameters to be considered for the better and safe design of structure. In the present study experimental data for non-reshaped berm breakwater are collected from Marine Structures Laboratory, Department of Applied Mechanics and Hydraulics, NITK, Surathkal, India. Soft computing techniques like Artificial Neural Network (ANN), Support Vector Machine (SVM) and Adaptive Neuro Fuzzy Inference system (ANFIS) models are constructed using experimental data sets to predict the damage level of non-reshaped berm breakwater. The experimental data are used to train ANN, SVM and ANFIS models and results are determined in terms of statistical measures like mean square error, root mean square error, correla-tion coefficient and scatter index. The result shows that soft computing techniques i.e., ANN, SVM and ANFIS can be efficient tools in predicting damage levels of non reshaped berm breakwater.
\end{abstract}

KEY WORDS: Berm breakwater; Damage; Artificial Neural Network; Support Vector Machine; Adaptive Neuro Fuzzy Inference system.

\section{INTRODUCTION}

Berm breakwaters are rubble mound structures constructed with the presence of horizontal berm at or above still water level (SWL) at the sea side. Berm breakwaters can be classified into statically stable structures and dynamically stable structures, depending on the behavior under design conditions (Moghim, Shafieefar, Tørum and Chegini, 2011). Statically stable structures are non reshaped structures, where no or minor damage is allowed to the structure under design conditions. The term "Damage" is defined as the displacement of armor units (Van der Meer, 1988). Relation used to measure the damage level (S) is

$$
S=\frac{A}{D_{n 50}^{2}}
$$

where, $\mathrm{A}$ is the area of erosion and $\mathrm{D}_{\mathrm{n} 50}=\left(\mathrm{M}_{50} / \rho_{\mathrm{a}}\right)^{1 / 3}$ is the nominal diameter of the stones. $M_{50}=$ median stone mass, $\rho_{a}=$ density of stone.

Breakwaters protect coasts or harbors against wave attack; they are also used for dual purposes like dissipating wave energy and providing loading facilities for cargo and passengers. From the past, many physical models were developed and experiments were carried out to design safe breakwaters (Priest, Pugh and Singh, 1964; Brun and Johannesson, 1976; Baird

Corresponding author: Sukomal Mandal

e-mail:smandal@nio.org 
and Hall, 1984; Van der Meer, 1988, 1992; Hall and Kao 1991; Tørum, Franziska and Andreas Menze, 2003; Subba Rao, Pramod and Rao, 2004; Subba Rao, Subrahmanya, Rao and Chandramohan, 2008) which are time consu-ming and expensive in terms of cost.

To minimize the cost and time in conducting the experimental work, the soft computing tools like Artificial Neural Network (ANN), Support Vector Machine (SVM), Adaptive Neuro Fuzzy Inference System (ANFIS), etc., are being widely used to predict outcome of the experimental results. These soft computing tools have been used in different fields (Sarjakoski, 1988; Kazperkiewiecz, Raez and Dubrawski, 1995; Voga and Belchior, 2006; Dong, Cao and Lee, 2005; Kavaklioglu, 2011). Also in the coastal field some works have been carried out using soft computing tools.

Mase, Masanobu and Tetsuo (1995) applied neural network technique to predict the stability and damage level of rubble mound breakwater, the predicted damage levels are matching with the measured damage levels which was experimentally carried out by Van der Meer (1988) and Smith, Kobayashi and Kaku (1992). Yagci, Mercan, Cigizoglu and Kabdasli (2005) used neural network technique to predict the damage ratio of breakwater. Model estimations of damage ratios were matching the predicted values by neural network method. The ANN application enables the consideration of wave period, wave steepness, breakwater slope and wave height in estimating damage ratio. Kim and Park (2005) applied the artificial neural network method to design the rubble mound breakwater. According to them the neural network technique gave more accurate results than the conventional empirical model and the extent of accuracy was affected by the structure of neural network. Mandal, Subba Rao and Raju (2005) used back propagation neural network technique to estimate ocean wave parameters from theoretical Pierson-Moskowitz spectra and measured ocean wave spectra. According to them the ocean wave parameters can be directly obtained from the measured spectra using trained neural network.

Mahjoobi and Mosabbeb (2009) used a regressive Support Vector Machine (SVM) for the prediction of significant wave height. Their results show that the SVM can be successfully used for the prediction of significant wave height $\left(\mathrm{H}_{\mathrm{s}}\right)$. Kim, et al. (2010) used Support Vector Regression to predict the stability number of armor blocks of breakwaters. The proposed method proves to be an effective tool for designers of rubble mound breakwaters to support their decision process and to improve design efficiency. Balas, Koc and Tur (2010) applied hybrid model for the preliminary design of rubble mound breakwater and a better agreement between the predicted and measured was obtained when compared to stability equations of Van der Meer (1988) and ANN. Patil, Mandal, Hegde and Alavandar (2011) used ANFIS model for predicting wave transmission coefficient of horizontally interlaced multilayer moored floating pipe breakwater and showed that ANFIS model outperformed ANN model for predic-ting transmitting waves. In the present paper, performances of the soft computing tools namely ANN, SVM and ANFIS for the prediction of damage level for non-reshaped berm breakwater are investigated.

\section{EXPERIMENTAL DATA}

The experimental work was carried out in Marine Structures Laboratory, Department of Applied Mechanics and Hydraulics, NITK, Surathkal, India. The wave flume is $50 \mathrm{~m}$ long, $0.71 \mathrm{~m}$ wide, $1.1 \mathrm{~m}$ deep, and has a $42 \mathrm{~m}$ long smooth concrete bed. Fig. 1 shows a sketch of the wave flume where a scaled model of berm breakwater is placed.

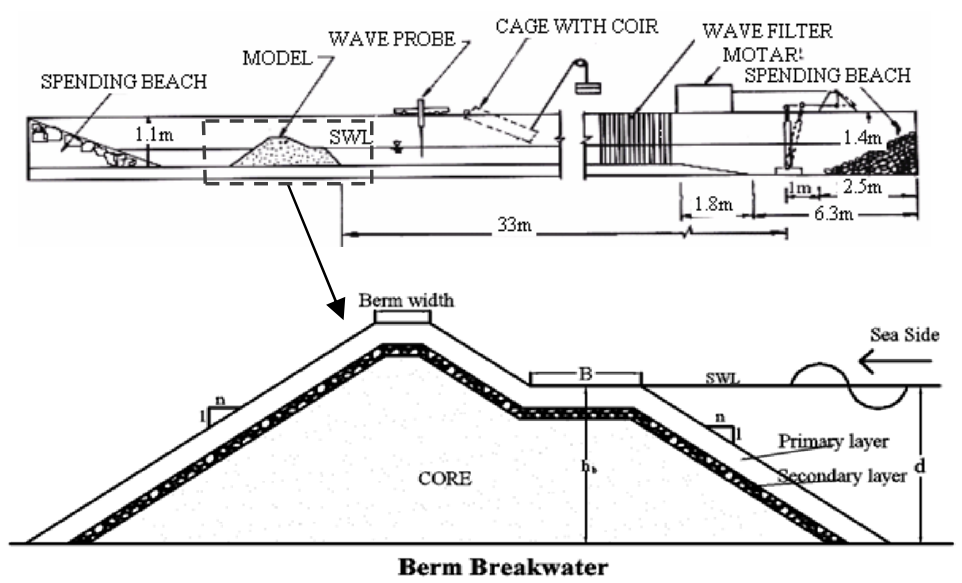

Fig. 1 Experimental set-up. 
Four set experiments were carried out for 3000 waves. In the first set of experiment, stability for different wave periods and height on conventional breakwater model with trapezoidal cross section with armour stone weight $\mathrm{W}_{50}=74$ gm was tested. In the second set of experiments, statically stable non-reshaped berm breakwater models were tested with the armour stones weight $\mathrm{W}_{50}=52 \mathrm{gm}$ which is about $30 \%$ less than $74 \mathrm{gm}$. They studied the influence of berm width on the stability of the breakwater, runup and rundown (Subba Rao, Pramod and Rao, 2004). In the third set of experiments armor stones weight $\mathrm{W}_{50}$ $=58.6 \mathrm{gm}$ which is about $20 \%$ less than $74 \mathrm{gm}$. The influence of tidal effect and stability were studied by changing the depth of water in front of the breakwater model. In the fourth set of experiments the influence of location of the berm and stability were studied by keeping the armor stones weight $\mathrm{W}_{50}=52 \mathrm{gm}$, the weight used in conventional breakwater (Subba Rao, Subrahmanya, Rao and Chandramohan, 2008). Range of experimental variables is shown in Table 1.

Many problems involving fluid motions are quite complex in nature. In the present case the complex flow phenomenon responsible for energy dissipation cannot be easily represented by mathematical equations and one has to rely on experimental investigations. The results of such investigations are more useful when expressed in the form of dimensionless relations. To arrive at such dimensionless relations of different variables, dimensional analysis is carried out. After conducting the dimensional analysis using Buckingham's- $\Pi$ theorem the dimensionless parameters namely wave steepness $\left(\mathrm{H}_{0} / \mathrm{L}_{0}\right)$, surf similarity $(\zeta)$, relative berm width by water depth $(\mathrm{B} / \mathrm{d})$, armor stone weight $\left(\mathrm{W}_{50} / \mathrm{W}_{\max 50}\right)$, relative berm width $\left(\mathrm{B} / \mathrm{L}_{\mathrm{o}}\right)$ and relative berm location $\left(\mathrm{h}_{\mathrm{B}} / \mathrm{L}_{\mathrm{o}}\right)$ were obtained.

For the present analysis, experimental data are converted into non dimensional parameters like $\mathrm{H}_{0} / \mathrm{L}_{\mathrm{o}}, \zeta, \mathrm{B} / \mathrm{d}, \mathrm{W}_{50} / \mathrm{W}_{\max 50}, \mathrm{~B} /$ $\mathrm{L}_{\mathrm{o}}$ and $\mathrm{h}_{\mathrm{B}} / \mathrm{L}_{\mathrm{o}}$ and they are used for the analysis. 124 data sets are considered for the present study. From 124 data sets randomly $93(75 \%)$ data sets are used for training the networks and $31(25 \%)$ data sets are used for testing the networks.

Table 1 Range of experimental variables.

\begin{tabular}{|c|c|}
\hline Variable & Range \\
\hline Wave height $\mathrm{H}(m)$ & $0.10,0.12,0.14,0.16$ \\
\hline Wave period $\mathrm{T}(\mathrm{Sec})$ & $1.6,2.0,2.6$ \\
\hline Water depth above the bed level d $(m)$ & $0.25,0.30,0.35,0.40$ \\
\hline Water depth above or below the berm $\mathrm{d}_{\mathrm{B}}(m)$ & $+0.08,+0.03,-0.02,-0.07$ \\
\hline Armor stone weight $\mathrm{W}_{50}(\mathrm{gm})$ & 52 to 74 \\
\hline Crest height above the seabed $(m)$ & 0.70 \\
\hline Berm width B $(m)$ & 0.60 \\
\hline Berm position above seabed $\mathrm{h}_{\mathrm{B}}(m)$ & 0.32 \\
\hline
\end{tabular}

\section{ARTIFICIAL NEURAL NETWORK}

The Artificial Neural Network (ANN) is mimicking of human brain which has the ability to learn and acquire knowledge by observing and can be used as a powerful tool for prediction. Many research activities have been carried out based on this method in different fields(Mase, Masanobu and Tetsuo, 1995; Yagci, Mercan, Cigizoglu and Kabdasli, 2005; Mandal, Subba Rao and Raju, 2005; Kim and Park, 2005; Hashemi, Ghadampour and Neill, 2010; Aydogan, et al., 2010; Iglesias, Castro and Fraguela, 2010).

Fig. 2 shows the architecture of neural network. The Feed Forward Network (FFN) commonly used for supervised learning which consists of three layers, namely I-number of nodes in input layer, M-number of nodes in hidden layer and o- number of nodes in output layer. These three layers are highly interconnected by nodes and work together to solve specific problems. Once the data is received in input layer the processed values are sent to the hidden layer. The hidden layer and output layer process all incoming signals by applying some weights to them. The Feed Forward Network (FFN) uses back propagation for training network where the error at the output layer is moved back to the input-hidden layers for updating weights and decrease errors to yield best results. The main aim of the FFN process is to reduce the overall error (E) between the observed and predicted values 
by adjusting the weights. And these weights are combined and processed through an activation function and released to the output layer.

In the present study the FFN with 6 inputs parameters ( $I=6$ ), namely $\mathrm{i}_{1}=\mathrm{H}_{\mathrm{o}} / \mathrm{L}_{\mathrm{o}}, \mathrm{i}_{2}=\zeta, \mathrm{i}_{3}=\mathrm{B} / \mathrm{d}, \mathrm{i}_{4}=\mathrm{W}_{50} / \mathrm{W}_{\max 50}, \mathrm{i}_{5}=\mathrm{B} / \mathrm{L}_{\mathrm{o}}$ and $\mathrm{i}_{6}=$ $h_{B} / L_{o}, M$ is the number of hidden layer nodes, here $M=5$ and o is one output layer node, here $o=$ damage level (S). The activation function used in the hidden layer is hyperbolic tangent sigmoid transfer function (tansig) and linear transfer function (purelin) in the output layer, and to train the network Levenberg-Marquardt (LM) Algorithm (trainlm) is used (Haykin, 1999).

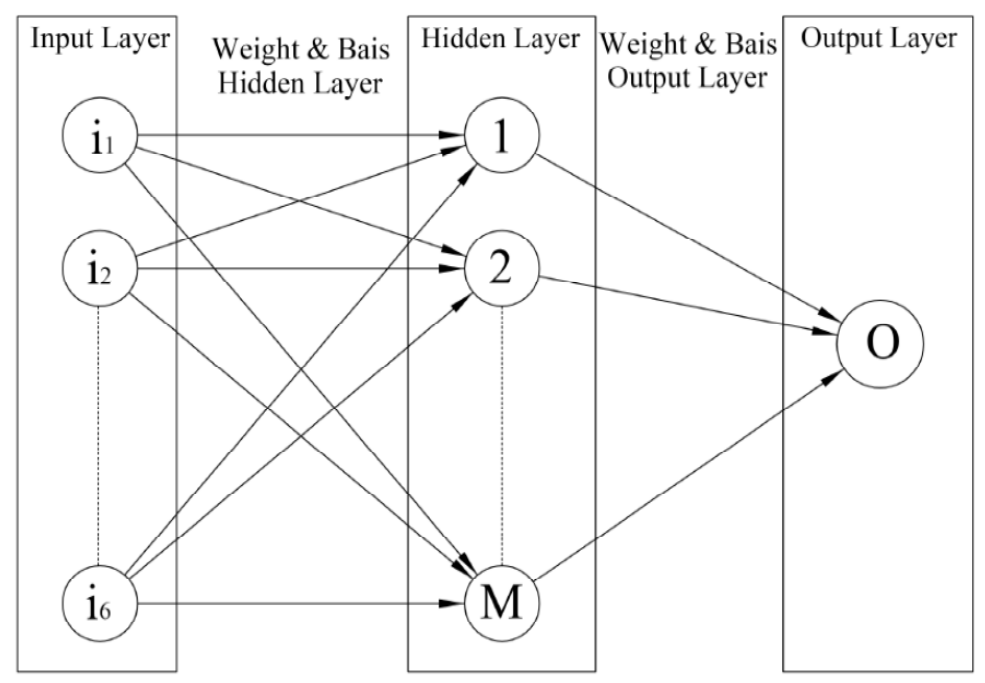

Fig. 2 Architecture of neural network.

\section{SUPPORT VECTOR MACHINE}

The Support Vector Machine (SVM) is a concept in computer science for supervised learning technique that is used for classification and regression analysis. The SVM for regression has been proposed by Vapnik, Golowich and Smola (1997). The model produced by SVM only depends on a subset of the training data, because the cost function for building the model ignores any training data that is close (within a threshold $\varepsilon$ ) to the model prediction (Smola and Scholkopf, 1998; Vapnik, 1995; Burges, 1998; Karatzoglou and Meyer, 2006). The SVM constructs a separate hyperplane between the classes in the n-dimensional space and maximizes the margin between two data sets of two input classes. It attempts to fit a curve, with respect to the kernel function used on the data points such that points lie between two marginal hyperplanes to minimize the regression error.

In SVM, for a given training data $\left\{\left(x_{1}, y_{1}\right), \ldots \ldots,\left(x_{i}, y_{i}\right)\right\}$ where $x_{i} \in R^{n}$ and $y_{i} \in[-\varepsilon,+\varepsilon] . x_{i}$ is the independent variables, $y_{i}$ is the dependent variable and $\mathrm{n}$ is the dimension of the independent variables. Fig. 3 shows the graphical representation of SVM.

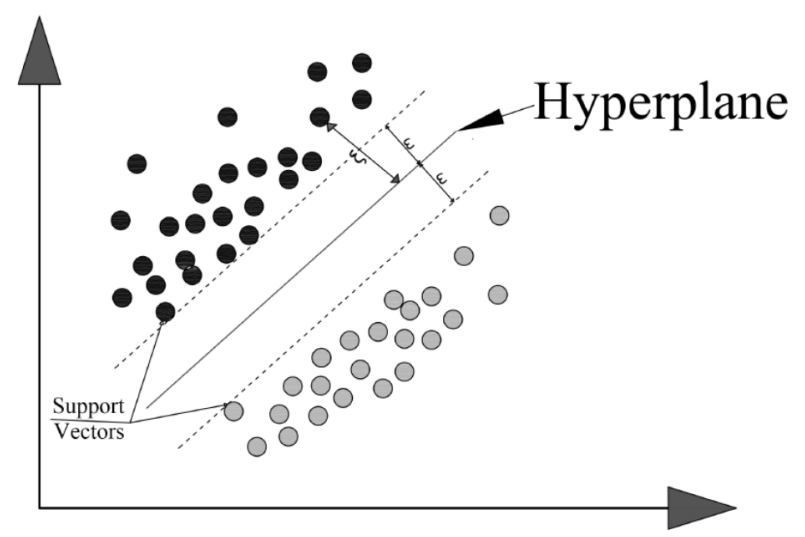

Fig. 3 General SVM. 
The SVM finds optimal hyper-plane that separates one class from other based on the quadratic programming technique. The quadratic programming can be written mathematically as:

$$
\frac{1}{2} \mathrm{w}^{\mathrm{T}} \mathrm{w}-\mathrm{C}\left(\mathrm{v} \varepsilon^{+}+1 / \mathrm{N} \sum_{\mathrm{i}=1}^{\mathrm{N}}\left(\xi_{\mathrm{i}}+\xi_{\mathrm{i}}^{*}\right)\right)
$$

which minimizes subject to:

$$
\begin{aligned}
& \left(\mathrm{w}^{\mathrm{T}} \emptyset\left(\mathrm{x}_{\mathrm{i}}\right)+\mathrm{b}\right)-\mathrm{y}_{\mathrm{i}} \leq \varepsilon+\xi_{\mathrm{i}}^{*} \\
& \mathrm{y}_{\mathrm{i}}-\left(\mathrm{w}^{\mathrm{T}} \emptyset\left(\mathrm{x}_{\mathrm{i}}\right)+\mathrm{b}_{\mathrm{i}}\right) \leq \varepsilon+\xi_{\mathrm{i}}, \\
& \xi_{\mathrm{i}} \xi_{\mathrm{i}}^{*} \geq 0, \quad \mathrm{i}=1,2, \ldots \mathrm{N}, \varepsilon \geq 0
\end{aligned}
$$

where $\phi\left(x_{i}\right)$ is the kernel used to transform data from the input (independent) to the high dimensional feature space, w is the weight vector, $\mathrm{b}$ is the bias term; $\mathrm{C}$ is the capacity constant and it should be noted that the larger the $\mathrm{C}$, the more the error is panalized so $\mathrm{C}$ should be chosen within limit to avoid over fitting and solved by using Lagrange technique. The parameter $\varepsilon$ controls the width $\varepsilon$-insensitive zone which is used to fit the training data. $\xi_{\mathrm{i}}, \xi_{\mathrm{i}}^{*}$ are slack variables (Vapnik, 1995). Slack variables $\xi_{\mathrm{i}}, \xi_{\mathrm{i}}^{*}$ are added to allow some errors for noisy data points. A kernel function is the inner product between two points in a suitable feature space and defining a notion of similarity with little computational cost even in very high-dimensional spaces.

In the present study kernel used is Radial Basis Function (RBF):

$$
\mathrm{k}\left(\mathrm{x}, \mathrm{x}^{\prime}\right)=\exp \left(-\gamma\left\|\mathrm{x}-\mathrm{x}^{\prime}\right\|^{2}\right)
$$

where $\gamma$ is the width of RBF function. RBF is general-purpose kernels used when there is no prior knowledge about the data (Karatzoglou and Meyer, 2006).

\section{ADAPTIVE NEURO-FUZZY INFERENCE SYSTEM}

The Adaptive Neuro-Fuzzy Inference System (ANFIS) was first introduced by Jang (1993). It is a combination of leastsquares and backpropogation gradient decent methods used for training Takagi-Sugeno type fuzzy inference system which is used for an effective search for the optimal parameters. It can provide a starting point for constructing a set of fuzzy 'if-then' rules with appropriate membership functions to generate the fixed input-output pairs. ANFIS is a simple structure with effective learning algorithm and high speed (Vairappan, Tamura, Gao and Tan, 2009). The advantage of a hybrid approach is that it converges much faster, since it reduces the search space dimensions of the backpropagation method used in neural networks.

\section{Architecture of ANFIS}

A simple architecture of ANFIS with I-input variables namely $i_{1}=H_{0} / L_{0}, i_{2}=\zeta, i_{3}=B / d, i_{4}=W_{50} / W_{\max 50}, i_{5}=B / L_{o}$ and $i_{6}=h_{B} / L_{o}$ and $\mathrm{o}$ is output variable i.e., $\mathrm{o}=$ damage level $(\mathrm{S})$ as shown in Fig.4. It consists of five layers and each layer is explained below.

- Layer 1

Every node in this layer is an adaptive node with a node function :

$$
\begin{aligned}
& \mathrm{O}_{1, \mathrm{i}}=\mu \mathrm{A}_{\mathrm{i}}(\mathrm{x}), \quad \text { for } \mathrm{i}=1,2 \\
& \mathrm{O}_{1, \mathrm{i}}=\mu \mathrm{B}_{\mathrm{i}-2}(\mathrm{x}), \text { for } \mathrm{i}=3,4
\end{aligned}
$$


$\mathrm{x}$ (or $\mathrm{y}$ ) is the input node and $\mathrm{A}_{\mathrm{i}}$ (or $\mathrm{B}_{\mathrm{i}-2}$ ) is a linguistic variables associated with the membership function of a fuzzy set $\left(\mathrm{A}_{1}, \mathrm{~A}_{2}, \mathrm{~B}_{1}, \mathrm{~B}_{2}\right)$.Typical membership function:

$$
\mu \mathrm{A}(\mathrm{x})=\frac{1}{1+\left[\frac{\mathrm{c}_{\mathrm{i}}}{\mathrm{a}_{\mathrm{i}}}\right]^{2 \mathrm{~b}_{\mathrm{i}}}}
$$

where $a_{i}, b_{i}$ and $c_{i}$ is the parameter set. Parameters are called as premise parameters.

- Layer 2

Each node in this layer is a fixed node, indicated by $\Pi$ Norm. The output is the product of all the incoming signals.

$$
\mathrm{O}_{2, \mathrm{i}}=\mathrm{w}_{\mathrm{i}}=\mu \mathrm{A}_{\mathrm{i}}(\mathrm{x}) \cdot \mu \mathrm{B}_{\mathrm{i}}(\mathrm{y}), \quad \mathrm{i}=1,2
$$

Output signal $w_{i}$ represents the fire strength of a rule.

- Layer 3

Each node in this layer is a fixed node $\mathrm{N}$ Norm. The $\mathrm{i}^{\text {th }}$ node calculates the ratio of the firing strength to the sum of the firing strength.

$$
\mathrm{O}_{3, \mathrm{i}}=\overline{\mathrm{w}}_{\mathrm{i}}=\frac{\mathrm{w}_{\mathrm{i}}}{\mathrm{w}_{1}+\mathrm{w}_{2}}, \quad \mathrm{i}=1,2
$$

Output signal $\bar{w}_{i}$ is called normalized firing strengths.

- Layer 4

Each node in this layer is an adaptive node, indicated by square node with a node function:

$$
\mathrm{O}_{4, \mathrm{i}}=\mathrm{w}_{\mathrm{i}} \mathrm{f}_{\mathrm{i}}=\mathrm{w}_{\mathrm{i}}\left(\mathrm{p}_{\mathrm{i}} \mathrm{x}+\mathrm{q}_{\mathrm{i}} \mathrm{y}+\mathrm{r}_{\mathrm{i}}\right)
$$

where $w_{i}$ is the normalized firing strength from layer $3 .\left\{\mathrm{p}_{\mathrm{i}}, \mathrm{q}_{\mathrm{i}}, \mathrm{r}_{\mathrm{i}}\right\}$ is the parameter set which are called as consequent parameters.

- Layer 5

Each node in this layer is a fixed node, indicated by circle node which computes the overall output as the summation of all incoming signals:

$$
\text { Overall output, } \mathrm{S}=\mathrm{O}_{5,1}=\sum_{\mathrm{i}} \overline{\mathrm{w}}_{\mathrm{i}} \mathrm{f}_{\mathrm{i}}=\frac{\sum_{\mathrm{i}} \mathrm{w}_{\mathrm{i}} \mathrm{f}_{\mathrm{i}}}{\mathrm{w}_{\mathrm{i}}}
$$

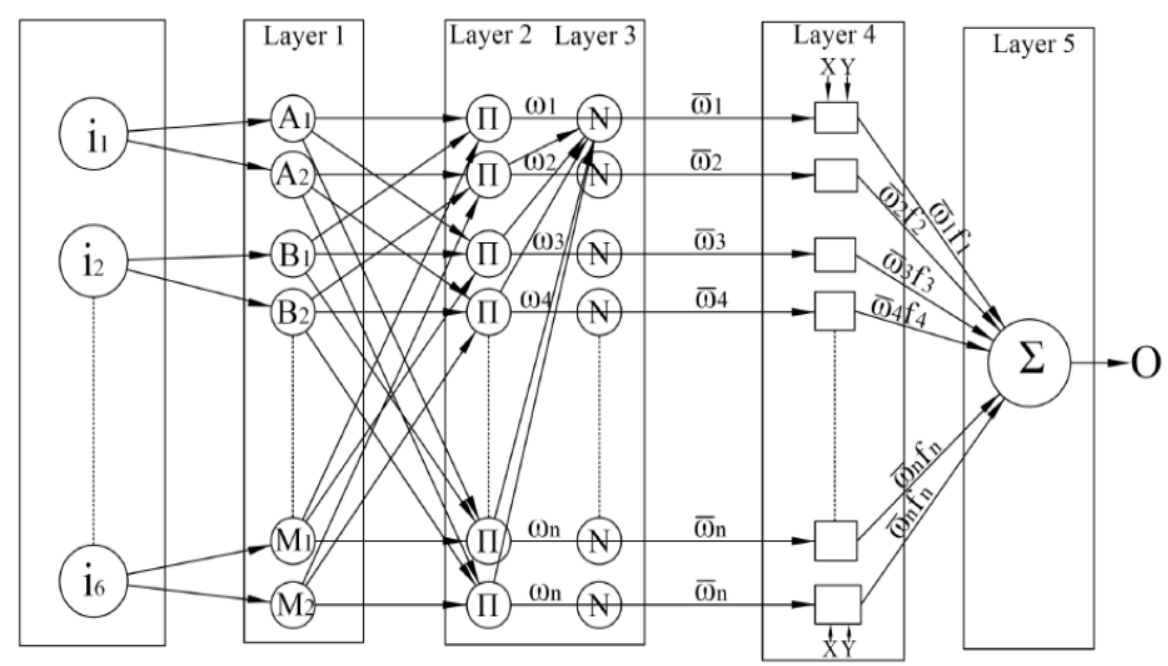

Fig. 4 ANFIS structure. 
In the present study ANFIS structure with first order Sugeno model with 2 generalised gauss membership function is assigned for input parameters and is obtained by

$$
f(x, \sigma, c)=e^{\frac{-(x-c)^{2}}{2 \sigma^{2}}}
$$

where $\mathrm{x}$ is input parameters, $\mathrm{c}$ and $\sigma$ are mean and variance respectively.

ANFIS model consists of 64 fuzzy rules for 6 input parameters and 1 output parameter. Figs 5a-5f show the initial membership function before training the model. When model starts training the gauss membership function it exhibits various forms of membership function on linguistic variables and changes accordingly. Figs. 6a-6f show the final membership function after training an ANFIS model.
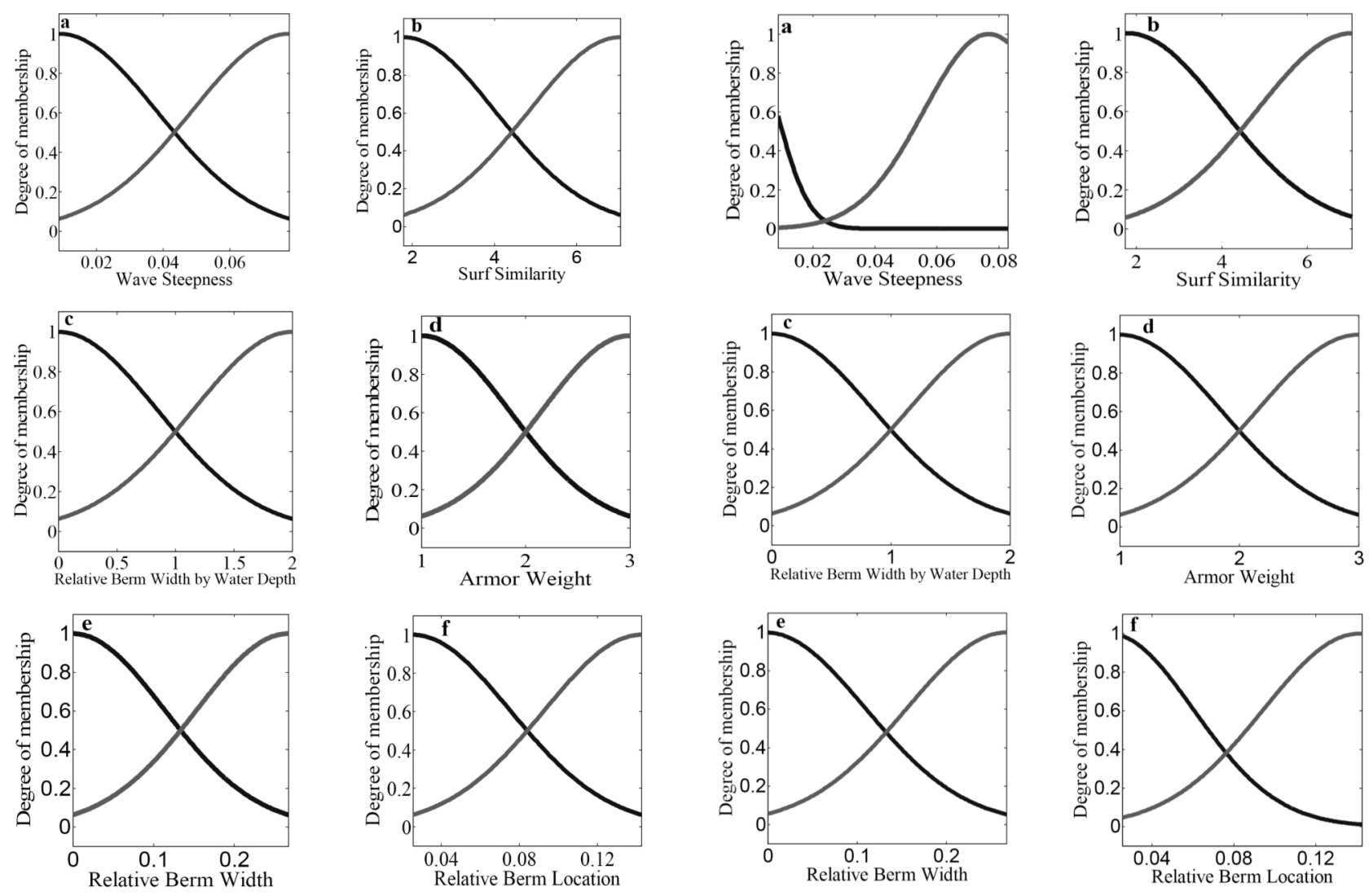

Fig. 5 a-f Initial membership functions of input parameters.

Fig. 6 a-f Final membership functions of input parameters.

\section{RESULTS AND DISCUSSION}

In the present study three models namely Artificial Neural Network (ANN), Support Vector Machine (SVM) and Adaptive Neuro Fuzzy Inference System (ANFIS) have been used to predict the damage levels of the non reshaped berm breakwater to reduce the time and cost for carrying the experimental work. The performance of the model is evaluated using statistical measures which are defined as follows:

Mean Square Error

$$
(\mathrm{MSE})=\frac{1}{\mathrm{n}} \sum_{\mathrm{i}=1}^{\mathrm{n}}\left|\mathrm{O}_{\mathrm{i}}-\mathrm{P}_{\mathrm{i}}\right|^{2} \times 100 \%
$$


Root Mean Square Error

$$
(\mathrm{RMSE})=\sqrt{\frac{1}{\mathrm{n}} \sum_{\mathrm{i}=1}^{\mathrm{n}}\left(\mathrm{O}_{\mathrm{i}}-\mathrm{P}_{\mathrm{i}}\right)^{2}} \times 100 \%
$$

Correlation Coefficient

$$
(\mathrm{CC})=\frac{\sum_{\mathrm{i}=1}^{\mathrm{n}}\left(\mathrm{O}_{\mathrm{i}}-\overline{\mathrm{O}}_{\mathrm{i}}\right)\left(\mathrm{P}_{\mathrm{i}}-\overline{\mathrm{P}}_{\mathrm{i}}\right)}{\sqrt{\sum_{\mathrm{i}=1}^{\mathrm{n}}\left(\mathrm{O}_{\mathrm{i}}-\overline{\mathrm{O}}_{\mathrm{i}}\right)^{2} \mathrm{X}\left(\mathrm{P}_{\mathrm{i}}-\overline{\mathrm{P}}_{\mathrm{i}}\right)^{2}}}
$$

Scatter Index

$$
(\mathrm{SI})=\frac{\mathrm{RMSE}}{\overline{\mathrm{O}}_{\mathrm{i}}}
$$

where, $\mathrm{O}_{\mathrm{i}}$ and $\mathrm{P}_{\mathrm{i}}$ are observed and predicted damage level respectively, $\mathrm{n}$ is the number of data set used and $\bar{o}_{i} \& \bar{p}_{i}$ are average observed and predicted damage level respectively.

In this study, soft computing tools like ANN, SVM and ANFIS are used to predict the damage level of non reshaped berm breakwater. Out of 124 experimental data sets, 93 data sets are used for training the network models and 31 data sets are used for testing the network models.

An ANN model for six input nodes and one output node with hidden layer starting from one node was constructed and analyzed by using LM algorithm. For 6-5-1 network with 300 epochs the ANN model gave an optimum result. Further with the increase in number of hidden layer nodes and epochs the output remains same or slightly improves, this could be owing to over fit the output values. Here we obtained higher CC and lower MSE values by using 5 hidden layer nodes and 300 epochs. In SVM, the model is trained by using the sequential optimization error function and parameters used in this study are capacity constant $\mathrm{C}=100$ and $v=0.5$ and the kernel function used is radial basis function with $\gamma=30$ to get a better result. In ANFIS model, a combination of the gradient descent algorithm and a least square algorithm is used for an effective search for the optimal parameters to yield good results. Based on this hybrid approach, correlations of training and testing are increased. Here Sugeno first order with 64 fuzzy rules and 2 generalised 'gauss' membership function are used to train the model.

The results obtained during training and testing processes for input parameters are calculated by means of statistical measures like correlation coefficient, mean square error, root mean square error and scatter index values as shown in Table 2. CCs in all three models are higher than 0.94 and 0.884 for trained and test data respectively. MSE and RMSE for all models are less than 5.879, 2.425, 12.412 and 3.523 for training and testing respectively. SI is less than 0.099 and 0.223 for training and testing respectively for all the models. Figs. 7-9 show the correlation between the observed and predicted damage levels for both training and testing for all three models.

The ANFIS model with 64 fuzzy rules and 2 generalized gauss membership function is used which reduces the processing time and gives better results for prediction of damage levels than ANN and SVM models. The ANFIS model outperformed ANN and SVM model and provided the best performance, i.e., highest CC for test output. Results of the study also indicate that the predictive capability of the ANFIS model used in this study is better when compared with ANN and SVM in damage levels prediction.

\section{SUMMARY AND CONCLUSION}

In the present study, the ability of soft computing techniques like ANN, SVM and ANFIS is applied to predict the damage levels for non reshaped berm breakwater. The experimental data generated by wave flume at Marine Structure laboratory, NITK, Surathkal, India is used in this study. From 124 data sets randomly 93(75\%) data sets are used for training the network and $31(25 \%)$ data sets are used for the testing the network. 
Table 2 Statistical measures for different model.

\begin{tabular}{|c|c|c|c|c|c|}
\hline \multirow{2}{*}{ Model } & & MSE & RMSE & CC & SI \\
\hline \multirow{3}{*}{ ANN } & Train & 5.879 & 2.425 & 0.940 & 0.203 \\
\cline { 2 - 6 } & Test & 12.412 & 3.523 & 0.884 & 0.267 \\
\hline \multirow{2}{*}{ SVM } & Train & 3.361 & 1.833 & 0.968 & 0.153 \\
\cline { 2 - 6 } & Test & 11.106 & 3.333 & 0.897 & 0.250 \\
\hline \multirow{2}{*}{ ANFIS } & Train & 1.445 & 1.202 & 0.985 & 0.099 \\
\cline { 2 - 6 } & Test & 8.463 & 2.909 & 0.919 & 0.223 \\
\hline
\end{tabular}

All the three models show good results in terms of statistical measures like mean square error, root mean square error, correlation coefficient and scatter index for observed and predicted damage levels. Among these models, the ANFIS structure which uses first order Sugeno model containing 64 rules and 2 generalized gauss membership functions yields improved results compared to ANN and SVM models.

From the present study we can conclude that the ANFIS model is an effective soft computing tool in predicting the damage level of non reshaped berm breakwater and it also reduces time and fast in predicting the values. Therefore it can be used as an alternative tool to determine the damage level of non reshaped berm breakwater.
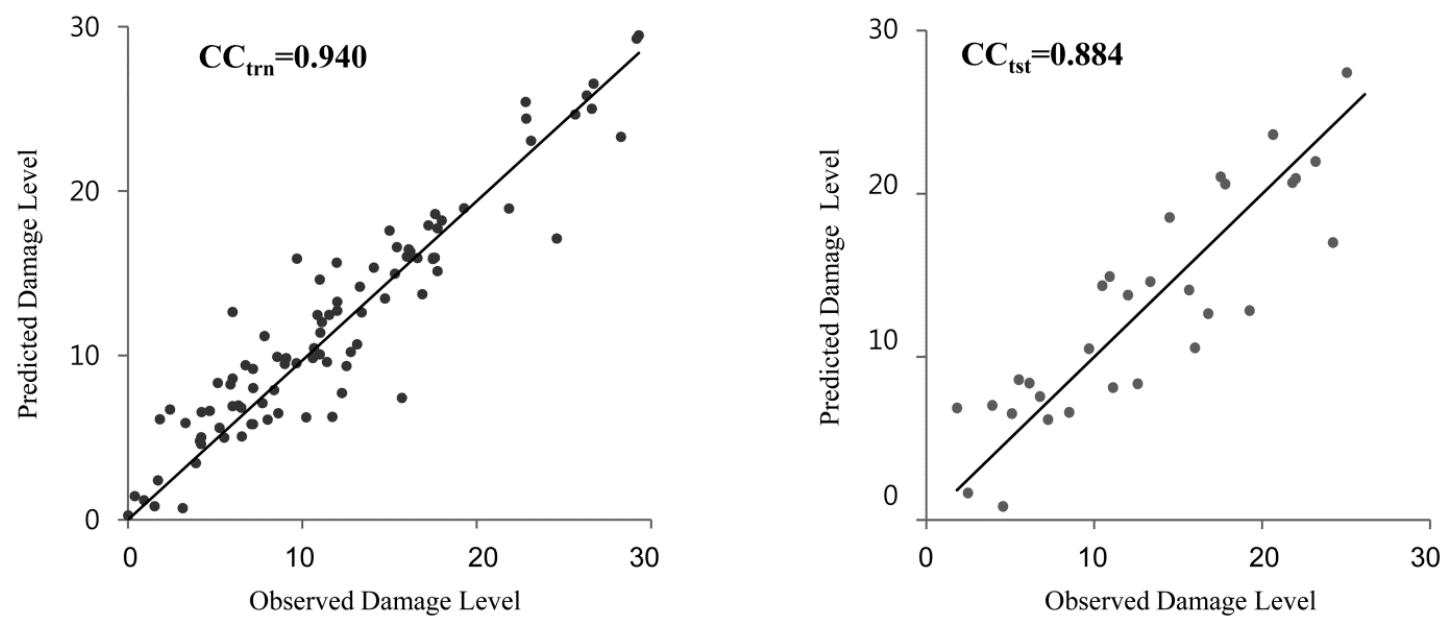

Fig.7 Observed and predicted damage level by ANN method for train and test data.
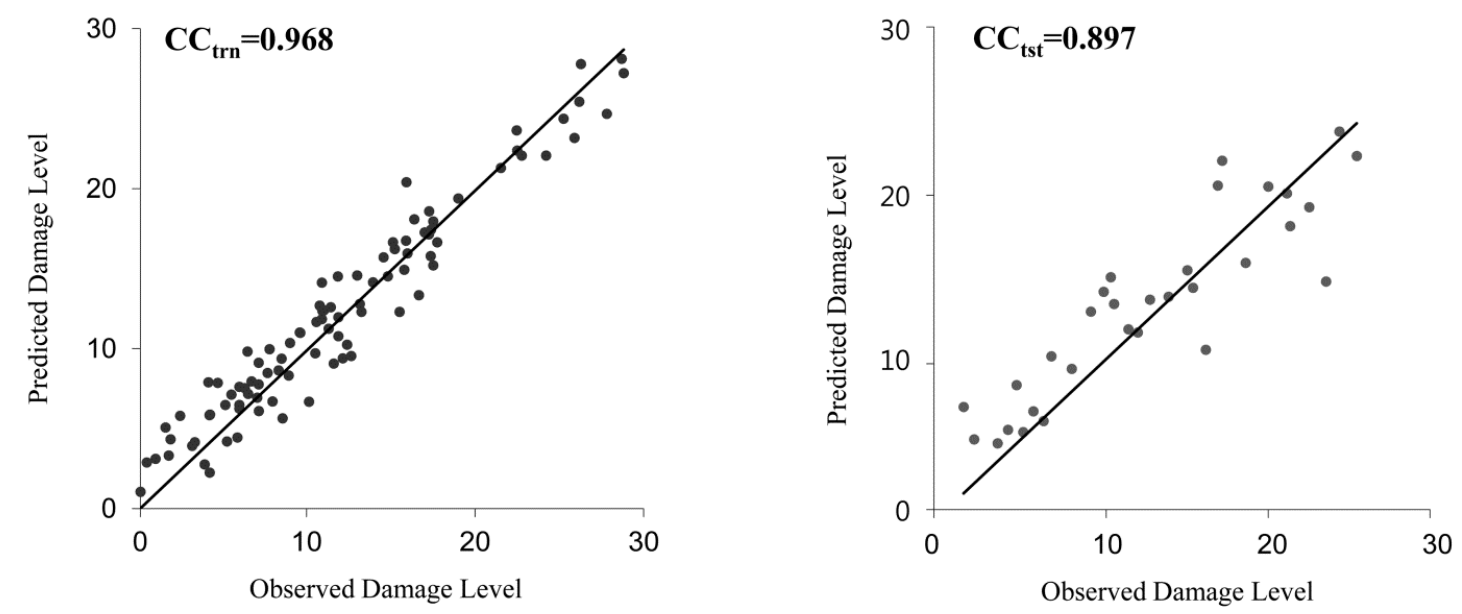

Fig. 8 Observed and predicted damage level by SVM method for train and test data. 

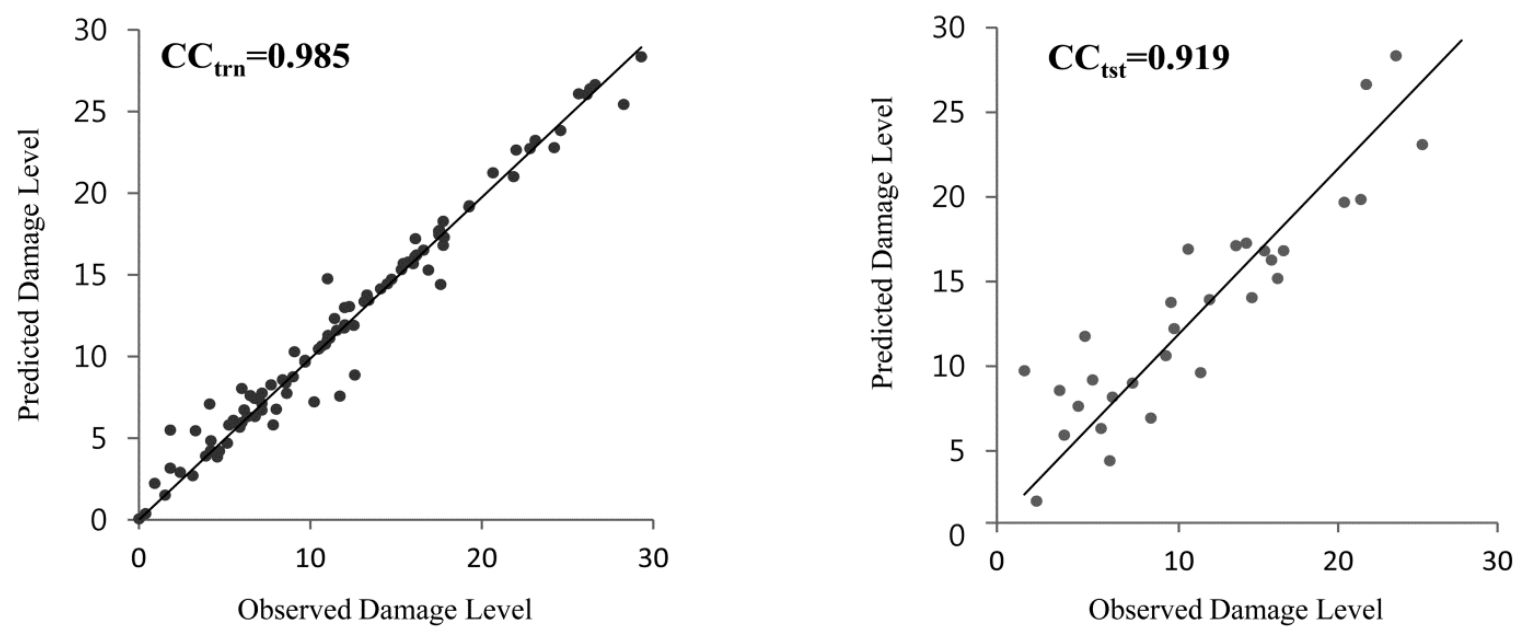

Fig. 9 Observed and predicted damage level by ANFIS method for train and test data.

\section{ACKNOWLEDGEMENT}

The authors are grateful to the Director, National Institute of Oceanography, Goa, India; Director, NITK Surathkal and Head, Department of Applied Mechanics and Hydraulics, NITK Surathkal, India for the support encouragement provided to them and for permission to publish the paper. NIO contribution paper number is 5184 .

\section{REFERENCES}

Aydogan, B., Ayat, B., Ozturk, M.N., Cevik, E.O. and Yuksel, Y., 2010. Current velocity forecasting in straits with artificial neural networks, a case study: Strait of Istanbul. J. Ocean Engineering, 37(5-6), pp.443-453.

Baird, W.F. and Hall, H.R., 1984. The Design of breakwaters using quarried stones. Proc., $19^{\text {th }}$ Int. Conf. On Coastal Engineering. pp.2580-2591.

Balas, C.E., Koc, M.L. and Tur, R., 2010. Artificial neural networks based on principal component analysis, fuzzy systems and fuzzy neural networks for preliminary design of rubble mound breakwaters. J. Applied Ocean Research, 32, pp. 425-433.

Brunn, P. and Johannesson, P., 1976. Parameters affecting stability of rubble mounds. Journal of the Waterways Harbors and Coastal Engineering Division, 102(2), pp.141-163.

Burges, C.J.C., 1998. A tutorial on support vector machine for pattern recognition. Data Mining and Knowledge Discovery, 2(2), pp.121-167.

Dong, B., Cao, C. and Lee, S.E., 2005. Applying support vector machines to predict building energy consumption in tropical region. J. Energy and Buildings, 37(5), pp.545-553.

Hall, K.R. and Kao, J.S., 1991. The influence of armor stone gradation on dynamically stable breakwaters. J. Coastal Engineering, 15(4), pp.333-346.

Hashemi, M.R., Ghadampour, Z. and Neill, S.P., 2010. Using an artificial neural network to model seasonal changes in beach profiles. J. Ocean Engineering, 37(14-15), pp.1345-1356.

Haykin, S., 1999. Neural Networks: A Comprehensive Foundation. Prentice-Hall. Nj 842.

Iglesias, G., Castro, A. and Fraguela, J.A., 2010. Artificial intelligence applied to floating boom behavior under waves and currents. J. Ocean Engineering, 37(17-18), pp.1513-1521.

Jang, J.S.R., 1993. ANFIS: Adaptive Network Fuzzy Inference System. IEEE Transactions on Systems, Man, and Cybernetics, 23(3), pp.665-685.

Karatzoglou, A. and Meyer, D., 2006. Support Vector Machines in R. Journal of Statistical Software, 15(9), pp.1-28.

Kavaklioglu, K., 2011. Modeling and prediction of Turkey’s electricity consumption using Support Vector Regression. $J$. Applied Energy, 88(1), pp.368-375. 
Kazperkiewiecz, J., Raez, J. and Dubrawski, A., 1995. HPC Strength prediction using artificial neural networks. ASCE Journal of Computing in Civil Engineering, 9(4), pp.279-284.

Kim, D.K., Kim, D.H., Chang, S.K., Lee, J.J. and Lee, D.H., 2010. Stability Number Prediction for Breakwater Armor Blocks USing Support Vector Regression. KSCE Journal of Civil Engineering, 15(2), pp.225-230.

Kim, D.H and Park, W.S., 2005. Neural network for design and reliability analysis of rubble mound breakwater. J. Ocean Engineering, 32, pp.1332-1349.

Mahjoobi, J. and Mosabbeb, E.A., 2009. Prediction of significant wave height using regressive support vector machines. $J$. Ocean Engineering, 36(5), pp.339-347.

Mandal, S., Subba Rao, and Raju, D.H., 2005. Ocean wave parameters estimation using backpropagation neural networks. J. Marine Structures, 18(3), pp.301-308.

Mase, H., Masanobu, S. and Tetsuo, S., 1995. Neural network for stability analysis of rubble mound breakwater. Journal of Waterway, Port, Coastal and Ocean Engineering, 121(6), pp.294-299.

Moghim, M.N., Shafieefar, M., Tørum, A. and Chegini, V., 2011. A New Formula for the Sea State and Structural Parameters Influencing the Stability of Homogeneous Reshaping Berm Breakwaters. Coastal Engineering, Elsevier, 58(8), pp.706-721.

Patil, S.G., Mandal, S., Hegde, A.V. and Alavandar, S., 2011. Neuro-fuzzy based approach for wave transmission prediction of interlaced multilayer moored floating pipe breakwater. J. Ocean Engineering, 38(1), pp.186-196.

Priest, M.S., Pugh, J.W. and Singh, R., 1964. Seaward profile for rubble mound breakwaters. Proc. 9th Int. Conf. on Coastal Engineering, ASCE. pp.553-559.

Sarjakoski, T., 1988. Artificial Intelligence in Photogrammetry. Elsevier Science Publishers B.V., 42(5-6), pp. $245-270$.

Smith, W.G., Kobayashi, N. and Kaku, S., 1992. Profile changes of rock slopes by irregular waves. Proceedings of 23th International Conference Coast Engineering ASCE. New York, NY, 1992, pp.1559-1572.

Smola, A.J. and Scholkopf, B., 1998. A Tutorial on Support Vector Regression. NeuroCOLT, Technical Report NC-TR98-030, Royal Holloway College, University of London, UK.

Subba Rao, Pramod, C.H. and Rao, B.K., 2004. Stability of berm breakwater with reduced armor stone weight. J. Ocean Engineering, 31(11-12), pp.1577-1589.

Subba Rao, Subrahmanya, K., Rao, B.K. and Chandramohan, V.R., 2008. Stability aspects of nonreshaped berm breakwaters with reduced armour weight. Journal of Waterway, Port, Coastal and Ocean Engineering, 134(2), pp.81-87.

Tørum, A., Franziska, K. and Andreas Menze., 2003. On berm breakwaters stability, scour, overtopping. J. Coastal Engineering, 49(3), pp.209-238.

Vairappan, C., Tamura, H., Gao, S. and Tan, Z., 2009. Batch type local search-based Artificial Neuro-Fuzzy Inference Systems (ANFIS) with self-feedbacks for time series prediction. J. Neuro computing, 72(7-9), pp.1870-1877.

Van der Meer, J.W., 1988. Deterministic and probabilistic design of breakwater armor layer. Journal of Waterway, Port, Coastal and Ocean Engineering, 114(1), pp.66-80.

Van der Meer, J.W., 1992. Stability of the seaward slope of berm breakwaters. J. Coastal Engineering, 16(2), pp.205-234.

Vapnik, V., 1995. The nature of statistical learning theory. Springer Berlin, New York.

Vapnik, V., Golowich, S. and Smola, A., 1997. Support Vector Method for Function Approximation, Regression Estimation, and Signal Processing. Mozer, M. Jordan, and T. Petsche, eds. Neural Information Processing Systems, 9, MIT Press, Cambridge, MA.

Voga, G.P. and Belchior, J.C., 2006. An approach for interpreting thermogravimetric profiles using artificial intelligence. $J$. Thermochimica Acta, 452(2), pp.140-148.

Yagci, O., Mercan, D.E., Cigizoglu, H.K. and Kabdasli, M.S., 2005. Artificial intelligence methods in breakwater damage ratio estimation. J. Ocean Engineering, 32, pp.2088-2106. 